\title{
The Relationship between Leader Member Exchange, Job Satisfaction and Affective Commitment, Gender-Similarity Roles in the Segregated Work Environment in the Kingdom of Saudi Arabia (KSA)
}

\author{
Mohammed Saad Alshamrani ${ }^{1}$ \\ ${ }^{1}$ Assistant Professor, Department of Management Studies, King Fahd Naval Academy (KFNA), The Kingdom of \\ Saudi Arabia \\ Correspondence: Mohammed Saad Alshamrani, Department of Management Studies, King Fahd Naval Academy \\ (KFNA), Box 2306 Jubail 31951, The Kingdom of Saudi Arabia. Tel: 966-533-138-844. E-mail: \\ msa999@hotmail.co.uk
}

Received: February 12, 2017

Accepted: March 22, 2017 Online Published: April 13, 2017

doi:10.5539/ijbm.v12n5p1

URL: https://doi.org/10.5539/ijbm.v12n5p1

\begin{abstract}
The purpose of this study is to assess gendered leadership in segregated work environments in the Kingdom of Saudi Arabia, a context in which interactions between the genders is limited. Throughout this study, leader-member exchange (LMX) will be classified as an independent construct, job satisfaction (JS) and affective commitment (AC) will be classified as dependent constructs, and gender similarity status will be classified as a moderator. Since interactions among the genders are uncommon in this context, this study will explore whether leadership relationships are gendered in this environment.

The data was collected using an online survey; 115 male teachers and 106 female teachers were included in the sample, all of whom work in segregated schools. The partial least squares approach to structural equation modeling was used (PLS-SEM), and the results showed that gender relationships are important when considering LMX. The results also proved that both genders of teacher are influenced by their relationship with their current principal, and this was important when predicting JS and AC. The multi-group analysis (MGA) test showed that gender moderates the relationship between LMX and JS with an advantage for female teachers.

The findings suggest that teacher training should pay more attention to minimising the stereotyping of females in relation to gendered leadership. The limitations and recommendations for future research are discussed in light of these findings.
\end{abstract}

Keywords: gender-similarity, leader-member exchange, job satisfaction, affective commitment, segregated work environment

\section{Introduction}

Leader-member exchange (LMX) theory explores the development of relationships between leaders and their followers in different types of scenarios (Kim \& Yukl, 1998). These relationships are characterised by the material resources, physical or mental effort, and emotional support exchanged between people (Wikaningrum 2007). These relationships affect psychological outcomes, such as job satisfaction and task performance, and these elements are explored in this study. However, relationships between the constructs can be affected by demographic factors. For example, gender-similarity within a unique context (such as a segregated work environment) can moderate such relationships.

Leader and follower characteristics are often researched as interactional factors, rather than separately. Furthermore, compatibility between the leader and their followers may affect the type of exchange that is ultimately formed. For example gender is significantly related to LMX (Liden, Sparrowe et al., 1997). The differences between male and female interaction is also a salient factor in organisations, and recent trends suggest that leadership practices are linked to gender. Some scholars suggest that leadership associations can be formed according to gender, and other scholars suggest that differences can be characterised according to gender roles(Eagly, Wood et al. 2000). Thus, it is unclear whether or not gender plays a part in moderating relationships and psychological outcomes (Kark, Waismel-Manor et al. 2012). To confuse the matter further, most researchers conduct leadership studies in contexts where genders often interact. However, in Saudi Arabia, interactions 
between the genders are mainly limited to relatives, or colleagues in specific situations (Al-Rasheed, 2013). In the majority of Saudi Arabian organisations, genders are segregated, based on the teachings of Islamic law (Bjerke \& Al-Meer, 1993). In Islamic cultures, segregation acts as way of maintaining respect between genders, and as protection from sexual harassment and discrimination. This is regardless of any underestimation of women's characteristics or management skills (Beekun \& Badawi, 1999).

The current study was developed based on using LMX as an independent construct, the two dependent constructs of job satisfaction and affective commitment, and gender-similarity as a moderator within the particular context of the segregated work environment. Previous research and developed hypotheses were used to formulate the constructs of interest these are outlined below. The research methodology incorporated measures, sampling and procedures, and measures and levels of analysis. The results of the study are also presented, together with a discussion about the implications of the research, and the limitations of study.

\section{Literature Review}

\subsection{Leader Member Exchange}

Over time, researchers of leadership theory have placed more and more focus on the interaction between leaders and various factors in a work situation. The nature of exchange is a two way series of interactions, whereby two people engage in mutual behaviours(Graen \& Cashman, 1975). This is the basis for building relationships, whether personal or professional (Allen and Turner de Tormes Eby 2012). The leader-member exchange (LMX) focuses on inter-personal relationships between leaders and followers. In general, these dyadic exchanges are thought to range on a continuum from high to low. High-quality exchanges are characterised by a higher level of trust, interaction, support and rewards, in comparison to low-quality exchanges (Lee, 2005). In fact, LMX theory is based heavily on social role theory, which evaluates behavioural responses when a leader delegates to followers, and explores how roles are defined. Reciprocity and negotiated rules are central in social exchange theory, in order to facilitate the accomplishment of obligations (Eagly, Wood et al., 2000).

The relationship between leaders and followers is established and developed through three stages: a) Role Taking, b) Role Making, and c) Role Routines. These stages are discussed below:

a) Role Taking: In this first stage, the member is evaluated by the leader. Then the leader assigns a role to the member (the role-taking stage). The leader goes about discovering the motivations and talents of each member, testing his or her response before assigning a role to the member.

b) Role Making: The significance of this stage is that the relationship goes one step further beyond role taking. This stage is influenced by the behaviour and characteristics of leaders and members.

c) Role Routines: The last stage is role routines (acquaintance stage), which is established when the relationship between the leader and follower becomes clear, understandable, expanded, and stable. Thus, the level of trust, respect and obligation between the pair should be high (Graen \& Uhl-Bien, 1995)

Throughout these stages, members are classified according to whether they are in the 'in-group' or 'out-group'. These dyads are found to emerge on the basis of how well subordinates work with their leaders, and how well their leaders work with them (Stringer, 2006).

\subsection{Job Satisfaction}

Job satisfaction is defined is an individual's subjective valuation of different aspects of their job (Hackman and Oldham, 1976, Locke, 1976). Many researchers view self-reported job satisfaction as a fascinating subjective element (Lévy-Garboua \& Montmarquette, 2004). Job satisfaction has been investigated as part of several disciplines, such as psychology, sociology, economics and management sciences. Employers might assume that their workers are satisfied, since employee satisfaction is closely related to labour market behaviour, such as productivity, but some researchers find that job satisfaction is related to wages (Gazioglu \& Tansel, 2006).

Different aspects of job satisfaction have been studied in previous research. These include job satisfaction as it relates to gender (Clark, Oswald et al., 1996), and relationships with managers and the work environment (Gazioglu \& Tansel, 2003). For example, the Saudi Arabian work environment is characterised by an extremely centralised system, where decisions are made from top to bottom, where there is a lack of autonomy, and where there is an enormous amount of bureaucracy. Some of these characteristics are classed as a cause of job dissatisfaction (Alzaidi, 2008).

\subsection{Affective Commitment}

Meyer and Herscovitch (2001,p.301) define commitment as, "a force that binds an individual to a course of action of relevance to one or more targets. As such, commitment is distinguishable from exchange based forms 
of motivation and from target-relevant attitudes, and can influence behaviour even in the absence of extrinsic motivation or positive attitude". Additionally, O'Reilly and Chatman (1986) argue that commitment is a multi-dimensional construct consisting of identification, compliance and internalisation. Identification occurs when a person accepts influence in order to set or maintain a satisfying relationship based on a need for affiliation. Here, commitment is treated and defined as a multi-dimensional construct (affective, continuance and normative). According to Meyer and Allen (1993, p. 13) "Affective commitment refers to the employee's emotional attachment to, identification with, and involvement in the organization...Continuance commitment refers to an awareness of the costs associated with having the organization". And with normative commitment, "the employee might experience a considerable degree of desire, need and obligation to remain with the current employer".

Other researchers define commitment as a uni-dimensional construct (Mowday, Porter et al., 1982), which measures the individual's identification of being involved with an organisation (affective commitment). The Organisational Commitment Questionnaire (OCQ) was developed based on three factors: (a) a strong belief in and acceptance of the organisation's goals and values, (b) a willingness to exert considerable effort on behalf of the organisation; and, (c) a strong desire to retain membership in the organization (Mowday, Porter et al. 1982).

For the current study, affective commitment is the point of focus, but mainly because in the context of this study including continuance commitment might affect the results of the gender moderation effect, because Saudi females are not responsible for paying for the cost of living, thus levels of continuance might be neglected for some female workers.

\section{The Philosophy of Gender Interaction in a Segregated Work Environment}

Women struggle against direct and indirect barriers to their self-development and their political, economic and social participation. Gender is not only how we identify ourselves but rather how others identify and relate to us, and how we are positioned within the social structure (Runyan \& Peterson, 2013). Issues relating to gender in the workplace are very important and complex (Cleveland, Stockdale et al., 2000). Furthermore, gender segregation has become a complex concept in women's studies, as feminists try to explain inequality in the work setting in a way that can emphasise the specificity of women's disadvantages and not reduce it to class (Leaper, 1994).

A discussion about gender segregation usually starts from the assumption that segregation itself is a form of inequality, or is related to inequality, and this is unquestionably taken to be an advantage for men (Blackburn and Jarman, 2006). However, actual circumstances are more complicated than this. The tendency, acceptance and outcomes of segregation vary from culture to culture. In Islamic nations, the policy of segregation of genders is observed in prayers, wedding ceremonies, public transport, and so forth (Chughtai \& Zafar, 2006). In fact, in religious nations the philosophy of gender segregation is complex. For example, in Saudi Arabia, the philosophy of segregation is derived from Islamic teaching, and is not perceived as intrinsically bad or good. From one perspective, it does not mean that women are controlled by men rather it is a sign of comfortable and proper business practice. Indeed, gender dissimilarity is seen as a mark of respect and reverence (Metcalfe, 2006; Metcalfe, 2007; Mimouni, Metcalfe et al., 2012). In interviews with female managers, Metcalfe (2007) notes that one interviewee responded as follows: "It is expected that men and women do business separately, it is what is culturally expected, but it is also proper...I prefer to develop business relations with women because I feel more comfortable and rely on them to support women...Men will usually support their male brothers and cousins." These views are an example of women's leadership practices in Saudi Arabia. This is how segregation is understood in Islamic culture. It is viewed as a kind of respect, regardless of any under-estimation of the skills and characteristics of women managers. McDowell and Bradley (2000) argue that the structures of horizontal segregation are more resistant to change, and in Saudi Arabia, women have suffered from stereotyping in work settings that are dominated by men (Alanazi, 2001). In Saudi Arabia, men and women work separately in the majority of organisations and there is little cross-gender interaction in the workplace. However, rare interaction contributes to negative stereotypical images of Saudi female leaders.

\section{Theoretical Model and Research Hypotheses}

With respect to the construct validation process (the measurement model step), the current study was developed as based on two antecedents: LMX: Individual level (leader characteristics) and group level (gender similarity in the segregated work environment), and two outcomes: job satisfaction and affective commitment. The following sections will discuss the development of the hypotheses.

\subsection{LMX and Job Satisfaction}

When considering the LMX classification of intrinsic 'in-group' and 'out-group' outputs, Dansereau et al. (1975) 
find that in-group members express higher levels of satisfaction, and a better attitude than that expressed by the out-group members. Indeed, Volmer, Niessen et al. (2011) conducted cross-sectional and longitudinal research, the results showed that the relationship between LMX and job satisfaction mutually influences the other, and people can shape their environment to take responsibility for careers and facilitate outcomes. (Durarajend, 2004) find there is a positive effect of LMX on job satisfaction. They use a multi-dimensional approach with four sub-scales: Affect, loyalty, contribution, and professional respect. In their meta-analysis of 79 independent research projects, Gerstner and Day (1997) find LMX to be more strongly related to outcomes, including satisfaction, performance ratings, and organizational commitment.

Therefore, the following hypothesis can be put forward for testing:

H1: There is a positive relationship between LMX and Job Satisfaction in a gender segregated work environment.

\subsection{LMX and Affective Commitment}

Leaders develop different relationships with subordinates through the LMX process. Leaders can establish low quality relationships (out-group) or high quality (in-group) relationships with their subordinates. In low-quality relationships, the leader implements formal authority, and allocates ordinary benefits in return for a standard job performance (economic exchange maintains the relationship). In a high-quality relationship a social exchange is developed, and attention, nurturing, support, and personal attachment move the relationship to a high level, and this is encouraged by mutual trust, respect, and obligation (Graen \& Uhl-Bien, 1995).

LMX describes work in terms of those who contribute more than expected, and those who contribute what is classed as 'standard' to an organisation. It explores the dyadic relationship between pairs, and it considers relationships that contribute to positive organisational outcomes such as performance (Dionne, Yammarino et al. 2002). In return for exemplary work performance, followers receive special privileges, career-enhancing opportunities, and increasing levels of care when they do their jobs. High-level social exchange relationships encourage stronger feelings, obligation, appreciation, and trust, more than basic economic exchanges do. Thus, high quality LMX is associated with the good performance of employees (Law, Wang et al., 2010). A meta-analysis conducted by Gerstner and Day (1997) finds that LMX is positively correlated to performance ratings, and organisational commitment, and negatively related to turnover.

It has been suggested that commitment occurs due to certain antecedents. (Mowday, Porter et al., 1982) classify the antecedences of commitment into four categories: a) Personal characteristics (demographic factors), b) Job characteristics (role-related characteristics), c) Work experience, and d) Organisational characteristics (structural characteristics). The effect of personal characteristics can be correlated according to demographic factors. For example, women are found to be more committed than men (Mathieu \& Zajac, 1990).

With this in mind the following hypothesis can be tested:

H2: There is a positive relationship between LMX and Affective Commitment in the gender segregated work environment.

\subsection{Gender Similarity: Gender Roles in the Work Environment}

Previous research does not provide a deep evaluation of the influence of gender similarity on leadership effectiveness. Most previous studies provide mean difference scores across gender in leadership styles, with the same and opposite gender, but no study has tested the influence of gender in a segregated work environment. However, there might be a general tendency for people to respond more positively to leaders relative to similarities. Leadership is a social process, and it is portrayed as an emergent process more than an achieved state. Thus, human interactions occur through relationships and networks of influence. These interactions are displayed by channels such as power, and some argue that men and women differ in their use of power (Fletcher 2004). Although the nature of interactions between different genders are not the main focus of this study, Carli (1999) argues that men possess higher levels of legitimate and expert power than women, while women display higher levels of referent power.

Furthermore, Carli (1999) argues that men are more influenced by competent men, while women are equally influenced by both men and women. Thus, issues connected with competence crop up less often for women, because women are perceived as having low legitimate power. Moreover, in face-to-face interactions, men are perceived as being stronger in influencing others than women are. Although competence is not measured in the current study, Avolio et al. (2004) find that competence mediates the relationship between leadership behaviour and organisational outcomes. As already mentioned, social roles are gendered and determined by a range of social, economic political and cultural factors (Takala \& Aaltio, 2004). Research conducted in Saudi Arabia 
finds that both genders display transformational behaviours, and followers prefer to work with transformational leaders (Al-Ammaj, 2001, Walker, 2004, Omer, 2005), experience human relationships with their immediate leaders (Assad, 2006) and express favourable attitudes toward democracy (Moaddel, 2006). However, this study was conducted in a single-sex environment.

In Saudi Arabia interaction between leaders and followers differs due to the roots of socialisation, traditional values, and Islamic teaching (Al-Rasheed 2002). Thus, it could be argued that gender roles in Saudi Arabia strongly affect leadership practices. For example, women in Saudi Arabia are expected to be wives and mothers, they are expected to help others, and display concern for followers (Assad, 2006). However, Saudi men are in charge of guardianship (Mimouni, Metcalfe et al., 2012). Therefore, in such a context, both genders believe that men have superiority over women in issues such as taking responsibility, and making decisions, albeit with consultation and the right to serve and influence. Therefore, men could have an advantage in exerting leadership over women. Guardianship has been found to be a disadvantage for women's mobility and career development (Minkus-McKenna 2009). Moreover, Saudi men report advantages for men in work (Budhwar, Mellahi et al., 2010). As a result, confidence and independence act as a bridge for men to engage in leadership. Conversely, their independence could restrict the ambitions of Saudi women from engaging leadership experience.

Gender is used as a moderator in this study. Gender similarity in the segregated work environment might be associated with LMX, and may help to establish the quality of the relationship that a subordinate develops with their managers (Dienesch \& Liden, 1986).

With this in mind, the following hypotheses can be put forward:

H4: Gender moderates the relationship between LMX and AC.

H5: Gender moderates the relationship between LMX and JS.

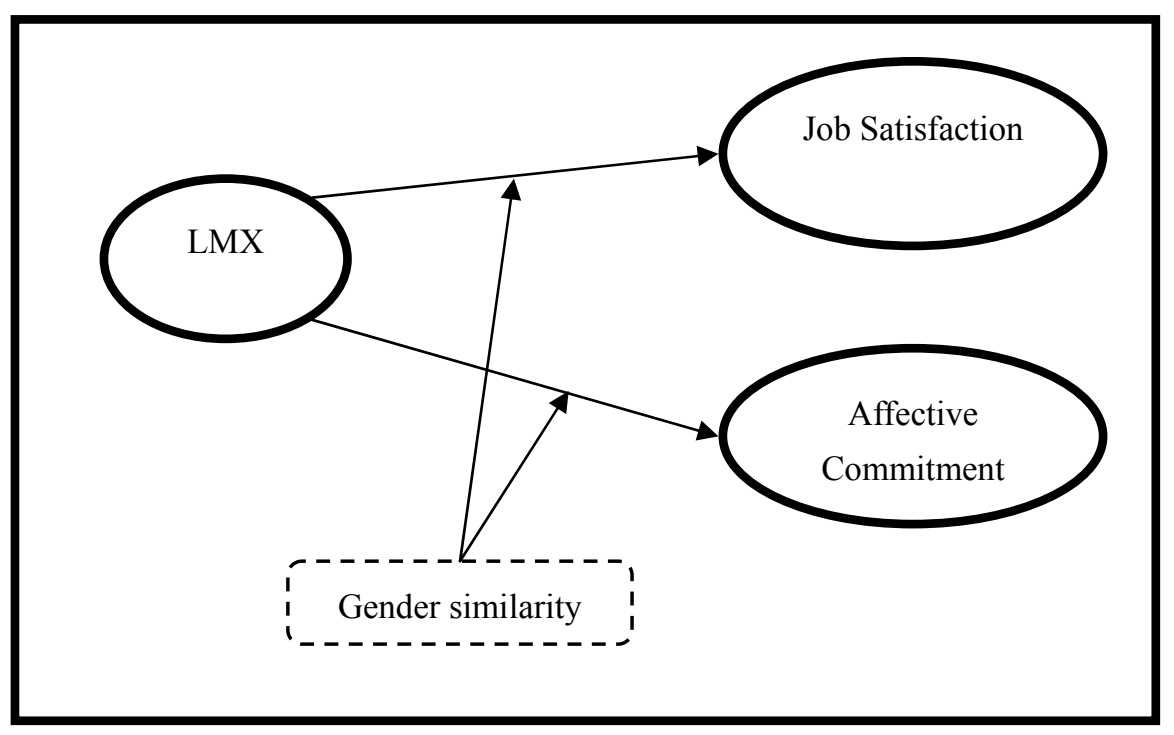

Figure 1. Framework

\section{Research Problems}

In Saudi Arabia, stereotypically, management is seen as a career only for men, and top managerial positions are appointed by and for men (Powell \& Graves, 2003). Globally, women managers are described as having to deal with limited career mobility, stereotypes and discrimination. Women managers are usually found in lower management positions that gave them little access to power (Omar \& Davidson, 2001). According to Eagly and Carli (2007) this is because of the cultural stereotype of leaders is relatively masculine, the mere activation of female stereotype can underestimate women's interest in leadership.

Saudi Arabia is a highly conservative and male-dominated culture. Due to traditional values, Saudi Arabia has operates a gender segregation policy throughout life, and, therefore, interactions between males and females is restricted to relatives and colleagues in specific situations (Taleb, 2010). Although the segregation policy 
facilitates interaction between the same-sex and protects females from male discrimination, it might keep Saudi women away from interacting with their counterparts (men) and participating as decision makers alongside men in political positions. Saudi Arabia's gender segregated policy has concealed women's abilities and prevented them holding high positions.

\section{The Significance of the Research}

Most previous studies that have compared male and female interaction have been conducted in a mixed gender-environment. Previous research has focused on how gender segregation works in Western culture. However, in some Eastern cultures, especially in cultures governed by Islamic law, gender segregation is institutional, and males and females are purposefully kept separate in a variety of scenarios, including education, employment, and leisure (Vidyasagar \& Rea, 2004). The background and consequences of gender segregation in a society where segregation is compulsory rather than optional varies extensively. Thus, there is a need for a study that investigates the impact of gender segregation in Eastern cultures (Mehta \& Strough, 2009). Johnson et al. (2006, p.141) claim that "we need to further develop our theoretical argument to take into account not only the activation of gender status beliefs, but also the activation of general gender stereotypes in the workplace".

\section{The Research Questions}

One main question can be applied to cover the scope of this research as follows:

"Does gender-similarity moderate the relationship between LMX and JS and between LMX and AC?"

\section{Methodology}

\subsection{Sampling and Procedures}

A total of 216 (111 male and 105 female) participants (teachers) were chosen for this study from schools all over Saudi Arabia. The following criteria were applied to the characteristics of the participants:

- Male and female (teachers) must have the same responsibilities.

- Pairs (principals and teachers) must have been working together for at least six months to ensure the relationship has developed.

- No references are to be made to the masculine or the feminine that might create prejudice.

\subsection{Measures}

Leader Member Exchange (LMX): The quality of the dyadic relationship between the headmaster and teacher was assessed using a version of the LMX-7 (Graen, Novak et al. 1982). The seven-item form is the standard measure of LMX and the most appropriate measure of LMX (Graen and Uhl-Bien 1995).

Job Satisfaction (JS): This was measured using a 14-item scale developed by Hackman and Oldham (1976). The measures were assessed using a 5-point scale ranging from 1 'strongly dissatisfied' to 5 'strongly satisfied'.

Affective Commitment (AC): This was measured using Allen and Meyer's eight items (Allen and Meyer, 1991). The measure was assessed on a five-point scale ranging from 1 'strongly disagree' to 5 'strongly agree'.

\subsection{Analysis Method}

The data was analysed using structural equation modeling (SEM), and Smart-PLS 2.0. "The power of SEM is seen most fully when multiple indicators for each latent variable are first tested through CFA to establish the conceptual soundness of latent variables used in the final structural model" (Schereiber et al., 2006, p. 335). The significance of Smart-PLS is its ability to evaluate the whole hypothesised model simultaneously. SEM can be broken down into two components:

(1) The measurement model/outer model, which shows how various indicators are related to latent constructs. Evaluation of the outer model is also referred to as confirmatory factor analysis (CFA). CFA specifies the measurement model delineating how latent variables are reflected by the observed constructs. Once a satisfactory measurement model is gained, path analysis can be explored by making links between latent variables (Goodhue, Lewis et al., 2007). Outer model assessment involves testing the individual indicators (squared standardised outer loading), reliabilities for each construct's composite of measures (internal consistency reliability), and the measures of convergence validity (average variance extracted, AVE) and discriminate validities (Hair, Sarstedt et al. 2012).

(2) The structural model/inner model specifies the relationship among latent constructs (e.g., direct effect, indirect effect (mediator), or no relationship), and this should be theoretically related either positively or negatively (Brown, 2006). The change in $\mathrm{R}^{2}$ was used to test the best model fit (Chin, 2010). 
PLS is appropriate to test the impact of gender moderation by dividing the data into groups. Group differences can be tested by comparing the ' $\mathrm{t}$ ' value (Eberl 2010). Once the data was divided into two groups, each group sample was not a large sample (below 200 cases), and so PLS was not affected by the sample size (Chin 2010). PLS was selected to test the effect of gender moderation on how the independent constructs predicted the dependent constructs.

A Smith-Satterthwait test was conducted to test the differences in $\beta$ value/relationships across gender (Chin, Marcolin et al. 2003). It was used because standard error inequality assumption is proved (Abbasi 2011). The formula for testing differences between the paths was applied as follows:

$$
\boldsymbol{T}=\frac{\text { path (malegroup })- \text { path }(\text { femalegroup })}{\sqrt{\text { s.e (malegroup })^{2}+\text { s.e. }(\text { femalegroup })^{2}}}
$$

\subsection{The Construct Validation Process}

According to O'Leary-Kelly and Vokurka (1998), validity can be assessed according to three types: content validity, construct validity and nomo-logical validity (the construct validation process). Content validity works to prove the group measurement items logically/theoretically, and to empirically assess the constructs (Nunnally, 1978). In this study construct validity was assessed using two common methods: convergent validity and discriminate validity. Convergent validity is the degree to which multiple methods of measuring a factor present the same results (O'Leary-Kelly \& J Vokurka, 1998), and it clarifies the correlation between responses (Chin 2010). The factor loading/outer in relation to cross-loading ought to be higher than factor loadings relating to other constructs. As suggested by (Anderson and Gerbing 1988), convergent validity can be assessed using four criteria: firstly the factor loading (FL) for each item should be over the recommended value (FL $>0.50$ ); secondly, the average of FL should be more than 0.5 ; thirdly, composite reliability (CR) should be more than 0.7 , and finally, the value of AVE should be more than 0.50. Loadings of 0.5 and 0.6 are considered acceptable. Discriminate validity ensures that each latent construct shares more variance with its own block of indicators than with another latent constructs, it and is approved when $\sqrt{ } \mathrm{AVE} \geq 0.5$.

The CFA/inner model was used because it is the most comprehensive method for testing construct validity. It uses only statistical analysis and outputs for assessing construct validity, such as the factor loading and factor correlation (O'Leary-Kelly \& Vokurka, 1998). Theoretically and empirically, nomo-logical validity explores the relationships between constructs (Hair, Black et al., 2006).

\section{Results and Discussion}

\subsection{Model Evaluation}

Because this study employed PLS for data analysis, there is no generally accepted global measure of the suitability of fit (Hair, Ringle et al., 2011). Therefore, as suggested by Chin (2010) the change in $\mathrm{R}^{2}$ was used to test the best model fit. The current study does not compete between models; a hypothesized model was selected based on the theoretical background. The outer model was assessed to investigate construct validity (Kraimer, Seibert et al. 1999). Figure 1 presets the factor loading for the model, and LMX6, JS13 and JS14 were eliminated from the model due to the factor loading being below 0.5. In PLS, the composite reliability was calculated automatically. The value of the composite reliability and cronbach alpha was acceptable at $>0.7$. The value of the reliability of the current study ranged between 0.88 and 0.96 , and these values exceed the minimum value of 0.7. However, reliability is a necessary but insufficient condition to assess validity (Morgan 1989). The values of AVE ranged between 0.64 and 0.68 , which exceeded the cut off value of 0.5 (Chin 1998). The model achieved a good model fit; the value of $\mathrm{R}^{2}$ for JS was 0.67 and 0.58 for AC. The significance of path estimation $(\beta)$ value was considered based on the results of the $t$ value $(p \leq 0.05)$ (Henseler, Ringle et al. 2009), thus any path with a $t$ value of below 1.96 was eliminated from the model, see Table 2. The results of $\beta$ and $t$ value and standard errors were obtained via using the PLS Bootstrap procedure - see Figure 3 (Chin 1998). 


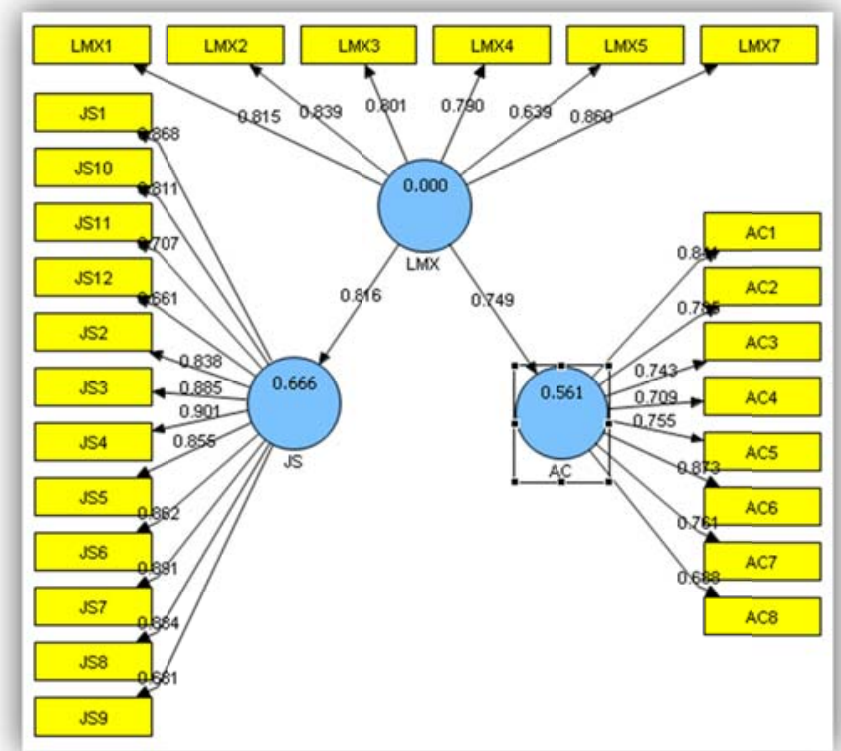

Figure 2. Factor loading and path coefficient and $\mathrm{R}^{2}(\mathrm{~N}=216)$

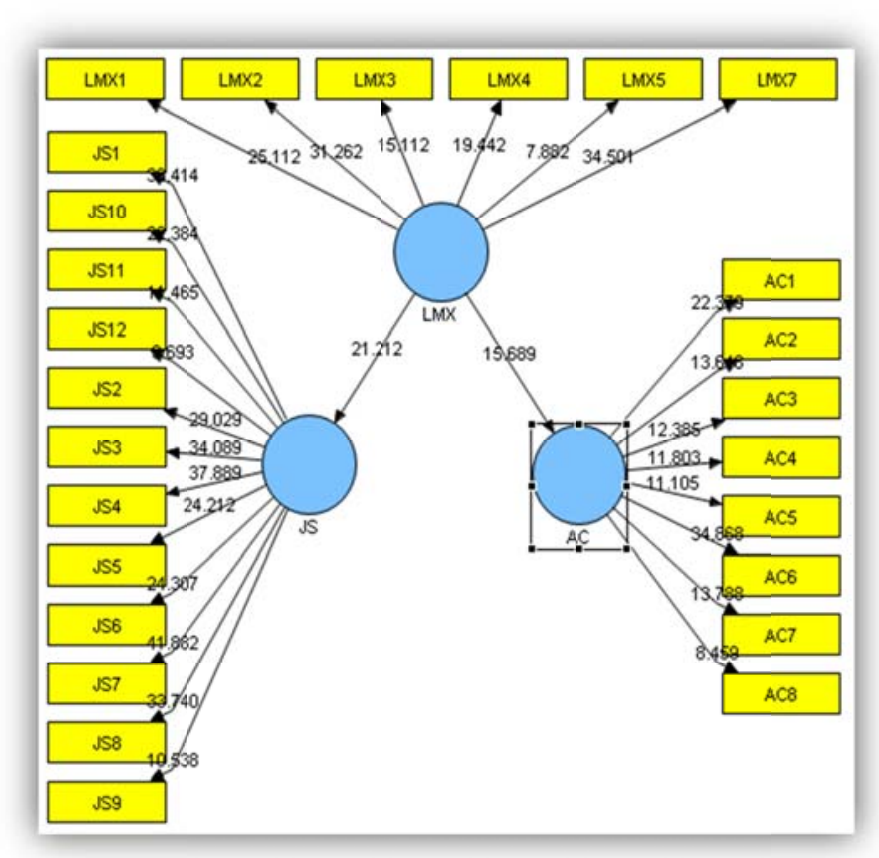

Figure 3. PLS based $t$-value and $\beta$ value $(\mathrm{N}=216)$

Table 1. AVE, $\sqrt{ } \mathrm{AVE}, \mathrm{CR}, \alpha, \mathrm{R}^{2}$ and correlation between constructs $(\mathrm{N}=216)$

\begin{tabular}{lllllllll}
\hline Construct & AVE & VAVE & CR & $\alpha$ & $\mathrm{R}^{2}$ & LMX & JS & AC \\
\hline LMX & 0.65 & 81 & 0.91 & 0.88 & & 1 & & \\
JS & 0.68 & 82 & 0.96 & 0.96 & 0.67 & 0.79 & 1 & \\
AC & 0.64 & 80 & 0.92 & 0.90 & 0.56 & 0.76 & 0.75 & 1 \\
Correlation is significant at the 0.01 level (2-tailed) & & & & & & \\
\hline
\end{tabular}




\subsection{Hypotheses Interpretation and Discussion}

H1: This hypothesis suggests that leader member exchange (LMX) has a positive relationship with JS. The result of the structural equation modeling indicates that the structural path between LMX and JS was positive and significant $(\beta=0.0 .82 t=21.67, p \leq 0.05)$. This indicates that there is a strong relationship between LMX and JS. LMX was found to be a perfect predictor and antecedent for increasing job satisfaction for followers in the Saudi context; thus, $\mathrm{H} 1$ is supported.

H2: This hypothesis suggests that leader member exchange (LMX) has a positive relationship with AC. The result of the structural equation modeling indicates that the structural path between LMX and AC was positive and significant $(\beta=0.0 .75 t=16.14, p \leq 0.05)$. This result indicates that there is a strong relationship between LMX and AC. TRFLs were found to be a perfect predictor and antecedent for increasing the affective commitment for followers in the Saudi context; thus, H2 is supported.

Table 2: Results of the relationship between constructs ( $\mathrm{N}=216$ )

\begin{tabular}{|c|c|c|c|c|c|}
\hline $\mathrm{H}$ & Relationship & $\beta$ & $\mathrm{t}$ & se & Remarks \\
\hline H1 & LMX $\triangleright \mathrm{JS}$ & 0.82 & 21.67 & 0.04 & * \\
\hline $\mathrm{H} 2$ & $\mathrm{LMX} \triangleright \mathrm{AC}$ & 0.75 & 16.14 & 0.05 & * \\
\hline \multicolumn{6}{|c|}{ Keys: $\beta=$ Coefficient path. $\mathrm{SE}=$ standard error. $\mathrm{T}=\mathrm{T}$-statistic } \\
\hline \multicolumn{6}{|c|}{$* \mathrm{p} \leq 0.05$} \\
\hline
\end{tabular}

The above results show that, according to LMX theory, teachers/employees who are classified as belonging in the 'in-group' receive more trust, respect and care from their current leaders, whereas employees who are classified as being in the 'out-group' receive less trust, respect and care than the in-group(Graen \& Uhl-Bien, 1995). It could be argued that such classification might encourage employees to form an attachment to their leader first, and this would encourage a sense of obligation by the schools to emerge. Such differentiation might spur competition among teachers to attain the leader's respect, trust and obligation. As a result of the LMX process, an attachment to the school might come second, whilst a commitment to the leader could act as a mechanism to obtain job satisfaction and affective commitment.

The above findings reveal the importance of LMX stages in the Saudi context. Cultural values might prove to be very important during LMX stages. For example, power distance results in Saudi Arabia were expected to be high, so involvement and interaction between teachers and their leaders is limited, and attaining the leader's satisfaction and mutual involvement would be appreciated by teachers. Thus, followers who build relationships with their leader would be very satisfied and then express an attachment to their schools. However, it is not clear which other particular behaviours might effectively enhance the level or quality of the relationship, or what levels of trust, respect and obligation should be applied to reach a high quality relationship, or what impact this high quality relationship has on selected groups. Wright et al. (1997) argue that, the LMX process does not imply intentional favouritism, discrimination or bias toward selected individuals.

Human resource management specialists need to be made aware of the positional biasing processes associated with high-quality LMX, and procedural checks and balances need to be applied to minimise such biases, if this is indeed possible. Otherwise, the development of high-quality LMX relations could result in organisational dysfunctional consequences and discrimination against out-group organization." Unfortunately, in the Saudi context, differentiation of groups could develop not only based on the work but, rather, based on unfair criteria, which are affected by culture (traditional values) (Ali and Al-Shakhis 1991, Al-Rasheed 2002, Al-Khatib, Malshe et al. 2008). However, this study confirms that LMX effective predictors increase the level of JS and AC in segregated work environments.

\subsection{Moderation Role of Gender Similarly (H3 and H4)}

Figures 4 and 5 present factor loading results across gender. It shows a satisfactory figure (FL $>0.5$ ). Furthermore, Table 3 shows the variance in dependent constructs as explained by independent constructs. $\mathrm{R}^{2}$ in the male sample was greater in AC $0.63(63 \%)$, while results in the female sample were $0.54(54 \%)$. However, in JS, $\mathrm{R}^{2}$ was higher in the female sample $0.71(71 \%)$, while it was $0.60(60 \%)$ in the male group. 


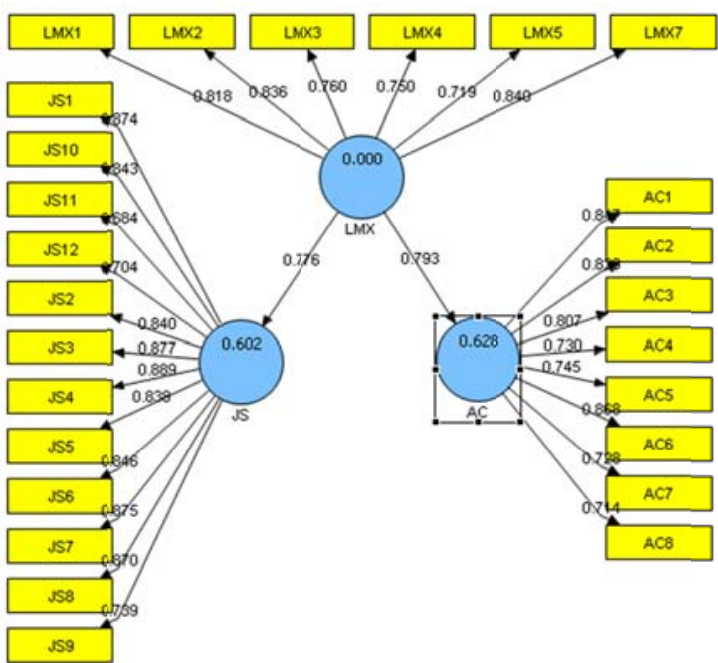

Figure 4. Factor loading and path coefficient and $\mathrm{R}^{2}$ for male model $(\mathrm{N}=111)$

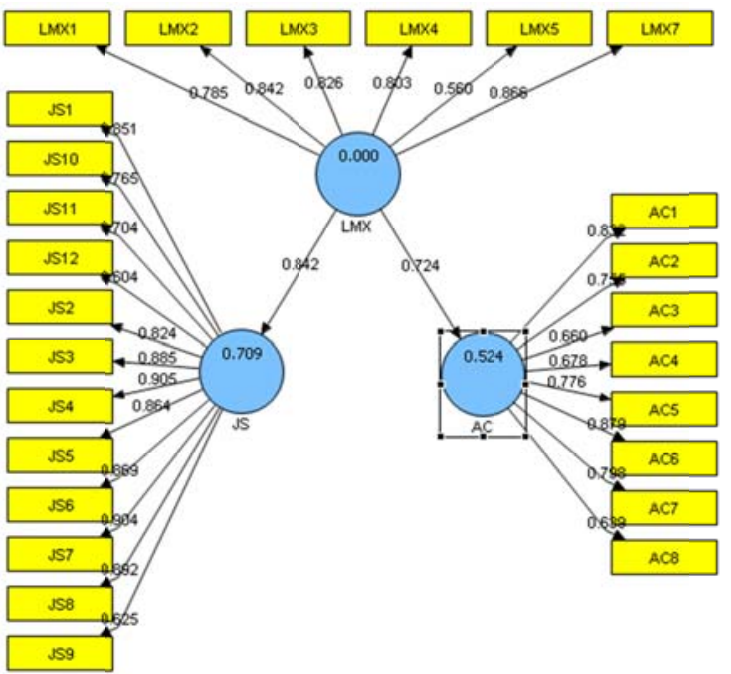

Figure 5. Factor loading and path coefficient and $\mathrm{R}^{2}$ for female model $(\mathrm{N}=106)$

Table 3. AVE, $\sqrt{ } \mathrm{AVE}, \mathrm{CR}, \alpha, \mathrm{R}^{2}$ and Correlation between constructs across gender

\begin{tabular}{llllllllll}
\hline & Construct & AVE & VAVE & CR & $\alpha$ & $\mathrm{R}^{2}$ & LMX & JS & AC \\
\hline Male & LMX & 0.66 & 0.81 & 0.91 & 0.88 & & 1 & & \\
& JS & 0.68 & 0.82 & 0.96 & 0.96 & 0.60 & 0.78 & 1 & 1 \\
\multirow{2}{*}{ Female } & AC & 0.65 & 0.80 & 0.93 & 0.91 & 0.62 & 0.79 & 0.74 & 1 \\
& LMX & 0.65 & 0.80 & 0.91 & 0.87 & & 1 & & \\
& JS & 0.66 & 0.81 & 0.96 & 0.95 & 0.70 & 0.75 & 1 & \\
\multicolumn{2}{l}{ Correlation is significant at the 0.01 level (2-tailed) } & & & & & & & & \\
\hline
\end{tabular}

The structural path results across gender are presented in Table 4. The two paths were assessed using the Smith-Satterthwait test. The observation of the Smith-Satterthwait test reveals that males and females behaved significantly differently across the LMX and JS path $(\mathrm{p} \leq 0.05)$. However, LMX AC was greater for males $(\beta=0.79, t=19.28, p \leq 0.05)$ than for females $(\beta=0.72, t=16.67, p \leq 0.05)$ but this result was insignificant. As a result of the Smith-Satterthwait test, it could be argued that females exceeded their counterparts (male) in 
practicing LMX in segregated work environment; therefore, $\mathrm{H} 3$ was supported and $\mathrm{H} 4$ was rejected.

Table 4. Structural path results across gender

\begin{tabular}{|c|c|c|c|c|c|c|c|c|c|}
\hline \multicolumn{5}{|c|}{$\operatorname{Male}(\mathrm{n}=111)$} & \multicolumn{5}{|c|}{ Female $(n=105)$} \\
\hline Relationship & $\beta$ & $\mathrm{t}$ & se & $\mathrm{R}^{2}$ & $\beta$ & $\mathrm{t}$ & se & $\mathrm{R}^{2}$ & $\begin{array}{c}\text { Smith-Satterth } \\
\text { wait test } \\
\text { results }\end{array}$ \\
\hline $\mathrm{LMX} \gg \mathrm{JS}$ & 0.78 & 14.44 & 0.05 & 0.60 & 0.84 & 33.99 & 0.02 & 0.70 & $3.52 *$ \\
\hline $\mathrm{LMX} \gg \mathrm{AC}$ & 0.79 & 19.28 & 0.04 & 0.62 & 0.72 & 16.67 & 0.05 & 0.52 & 1.36 \\
\hline $\begin{array}{l}\text { Keys: } \beta=\text { Coefficient } p \\
{ }^{*} p \leq 0.05\end{array}$ & tandarc & ror. $\mathrm{T}=$ & atistic & & & & & & \\
\hline
\end{tabular}

Eagly (2005) argues that the absence of significant differences between men and women in leadership styles could open up new opportunities for women. She argues that increasing gender differences will undermine women's social and political agenda. On the other hand, Hare-Mustin and Marecek (1994) believe that a lack of differences between genders will not serve the feminist cause. For example, due to natural and cultural attribution toward gender participation in a research context, women need to be treated differently from men.

This study confirms that Saudi female managers are stereotypically affected by the predominant perception of men as leaders in the Saudi context. Dorfman, Howell et al. (1997) argue that gender is something we do, not something we are. Eagly and Carli (2003) argue that women face challenges to prove the high level of capability required to be a leader. Some bias could prevent women from exhibiting leadership qualities (Garcia-Retamero \& López-Zafra, 2006). For example, discrimination and prejudice against women exist in Arab work environments (Yaseen 2010). Eagly and Karau (2002) argue that detrimental reactions not only limit women's access to leadership roles, but can also decrease the effectiveness of women who reach these roles. The activation of beliefs about women and men by gender-related cues influences people to perceive individual women as communal but not very agentic and individual men as agentic but not very communal (Eagly, Johannesen-Schmidt et al., 2003). Moreover, "expectation states theory argues that it is the status element of gender stereotypes that causes such stereotypes to act as distinctively powerful barriers to women's achievement of positions of authority, leadership, and power" (Ridgeway \& Smith-Lovin, 1999, p. 638). Thus, gender is unlikely to be salient in a segregated organisation.

This study argues for Saudi human resource management to start thinking about minimising the stereotyping of gendered leadership, and one possible tool for doing this is to examine the segregation policy. In fact, culturally, women in Saudi Arabia are still far from being effective in a mixed gender environment. In Saudi Arabia, the majority of organisations do not encourage the genders to interact. Therefore, the notion of "segregation policy facilitation" might facilitate easy interaction between pairs and women might find this helpful in fulfilling a leadership role. In addition, looking at gender composition effects could be a positive advantage for Saudi female managers who work according to a segregated policy. According to expectation states theory, gender effects depend on the salience of gender as a status characteristic. For example women's lower status in relation to men's is particularly highlighted in interactions between men and women. Consequently, women's relative advantage in influencing others would likely be weak in their interactions with their counterparts. Moreover, male resistance to female influence is certainly one way in which men can keep their power advantage over women (Carli, 2001). Thus, I would argue that a segregation policy, in contexts that underestimate and have negative attitudes to female leadership roles, is a very important element to consider for Saudi female leaders when practicing their leadership roles. Furthermore, gender stereotypes indicate that women are perceived to be less knowledgeable and expert, except in situations that favour female expertise (Carli, 1999).

Finally, this research argues that leadership is not necessarily gendered in a segregated work environment, where the gender state is not salient. Saudi women might not face unfair evaluation based on stereotypical judgments of men, and so may not have to resist such problems, which can emerge when they work face to face with men. Also, a segregated organisation might be a good "fertile environment" for female leaders in the Saudi Arabian context. However, other problems could emerge due to other demographic factors, or problems relating to gender states outside of segregated organisations that could prevent career movement for women.

Despite the barriers (stereotypical issues) that hinder Saudi women from participating effectively in high positions in government, it is interesting to speculate on findings that Saudi female managers should be 
self-motivated in order to increase the chance of minimising gendered stereotypes in relation to leadership. This is especially salient because gender states are absent in the bank environment due to the segregation policy. The results indicate an advantage of 'Saudi female leadership', as they show that Saudi female managers are qualified to engage with different leadership styles and establish relationships with their followers in order to increase organisational outcomes.

\section{Study Limitations}

In Saudi Arabia, due to traditional and Islamic values, establishing rapport with females is a highly sensitive issue, and it is not acceptable for genders to mix unless with relatives or colleagues under specific circumstances. The data for this research was collected by means of a face-to-face questionnaire, and in this endeavour the researcher found that making contact with males was easier than making contact with females. One of the objectives of using a face-to-face questionnaire was to judge the readiness of the respondents' participation, but this idea could not be applied with the female respondents due to religious and cultural reasons; in fact, traditionally, the researcher would be embarrassed to explain the objectives of the questionnaire even by telephone. These limitations always arise for Saudi males generally, and apply to when a male researcher is trying to conduct research in a female environment and vice versa.

Another limitation concerned conducting this study in educational institutions, because this had an effect on the genralisation of the results. Although the sample structure allowed the researcher to achieve the objectives of the study, different sectors have different managerial environments (where males and females work together in the same organisation and can interact). This gives rise to different ways of interaction between genders. Also, leadership styles across different positions and across hierarchies might differ.

\section{Recommendations for Further Study}

Levels of analysis are very important in leadership studies. This study relied heavily on the teachers' perspectives, so it would be useful to conduct comparative research between managers and subordinates to identify how organisational outcomes are influenced by different perceptions. Therefore, it is not sufficient to believe that followers have a good relationship with their leaders; the point is how the perceptions of both leaders and followers compare (dyadic).

This study focused on a segregated organisation, where males and females had no interaction. An important area for future research would be to conduct a comparative study between males and females in organisations, in which males and females work together. However, contextually, some aspects should be considered, such as the level of masculinity and femininity of the context, and the degree of discrimination across gender of leadership in the organisation. For example, the health sector and banks (main administration) could be the best examples to be considered, as these contexts are not regarded as specifically masculine or feminine in Saudi Arabia leadership culture. The significance of such a study would be to compare between same and opposite gender relationships in the same organisation. A review of previous research shows that such study has not yet been conducted in the Saudi context.

Furthermore, a prior phase (interview) would be suggested for further research, but the possibility of interviewing Saudi females is limited for male researchers and this issue needs to be taken into consideration to prevent any problem of common bias or desirable response issues.

\section{References}

Abbasi, M. S. (2011). Culture, demography and individuals' technology acceptance behaviour: A PLS based structural evaluation of an extended model of technology acceptance in South-Asian country context, Brunel University Brunel Business School.

Al-Ammaj, F. H. (2001). An investigation of leadership style and organizational commitment among Saudi public employees, Mississippi State University.

Alanazi, F. M. (2001). The Revised Self-Consciousness Scale: An assessment of factor structure, reliability, and gender differences in Saudi Arabia. Social Behavior and Personality: An International Journal, 29(8), 763-776. https://doi.org/10.2224/sbp.2001.29.8.763

Ali, A., \& Al-Shakhis, M. (1991). Changing managerial values in Saudi Arabia. Advances in International Comparative Management, 6(81), 102.

Al-Khatib, J. A. et al. (2008). Perception of unethical negotiation tactics: A comparative study of US and Saudi managers. International Business Review, 17(1), 78-102. https://doi.org/10.1016/j.ibusrev.2007.12.004

Allen, N. J., \& Meyer, J. P. (1993). Organizational commitment: evidence of career stage effects? Journal Of 
Business Research, 26(1), 49-61. https://doi.org/10.1016/0148-2963(93)90042-N

Allen, T. D., \& Turner de Tormes Eby, L. (2012). The study of interpersonal relationships: An introduction. Personal Relationships. The Effect on Employee Attitudes, Behavior, and Well-being, 3-14.

Al-Rasheed, M. (2002). A History of Saudi Arabia. Journal of Energy Literature, 8, 85.

Al-Rasheed, M. (2013). A most masculine state: Gender, politics and religion in Saudi Arabia. Cambridge University Press.

Alzaidi, A. M. (2008). Secondary school head teachers' job satisfaction in Saudi Arabia: The results of a mixed methods approach. ARECLS, 5, 161-185.

Anderson, J. C., \& Gerbing, D. W. (1988). Structural equation modeling in practice: A review and recommended two-step approach. Psychological bulletin, 103(3), 411. https://doi.org/10.1037/0033-2909.103.3.411

Assad, S. W. (2006). Supervision and Role Models among Saudi Female Workers. JKAU: Art and Humanities, 14, 3-19. https://doi.org/10.4197/art.14-1.1

Avolio, B. J. et al. (2004). Multifactor leadership questionnaire: Manual and sampler set. Mind Garden Redwood City, CA.

Beekun, R., \& Badawi, J. (1999). The leadership process in Islam. Proteus Shippensbutg, 16, 33-38.

Bjerke, B., \& Al-Meer, A. (1993). Culture's consequences: management in Saudi Arabia. Leadership \& Organization Development Journal, 14(2), 30-35. https://doi.org/10.1108/01437739310032700

Blackburn, R. M., \& Jarman, J. (2006). Gendered occupations exploring the relationship between gender segregation and inequality. International Sociology, 21(2), 289-315. https://doi.org/10.1177/0268580906061380

Brown, T. (2006). CFA with equality constraints, multiple groups, and mean structures. Confirmatory factor analysis for applied research, 236-319.

Budhwar, P. S. et al. (2010). Males' attitudes towards working females in Saudi Arabia. Personnel Review, 39(6), 746-766. https://doi.org/10.1108/00483481011075594

Carli, L. L. (1999). Gender, interpersonal power, and social influence. Journal of Social Issues, 55(1), 81-99. https://doi.org/10.1111/0022-4537.00106

Carli, L. L. (2001). Gender and social influence. Journal of Social Issues, 57(4), 725-741. https://doi.org/10.1111/0022-4537.00238

Chin, W. W. (1998). The partial least squares approach to structural equation modeling. Modern Methods For Business Research, 295(2), 295-336.

Chin, W. W. (2010). Bootstrap cross-validation indices for PLS path model assessment. Handbook Of Partial Least Squares, Springer, 83-97. https://doi.org/10.1007/978-3-540-32827-8_4

Chin, W. W. (2010). How to write up and report PLS analyses. Handbook Of Partial Least Squares, Springer: 655-690. https://doi.org/10.1007/978-3-540-32827-8_29

Chin, W. W. et al. (2003). A partial least squares latent variable modeling approach for measuring interaction effects: Results from a Monte Carlo simulation study and an electronic-mail emotion/adoption study. Information Systems Research, 14(2), 189-217. https://doi.org/10.1287/isre.14.2.189.16018

Chughtai, A. A., \& Zafar, S. (2006). Antecedents and consequences of organizational commitment among Pakistani university teachers. Applied HRM Research, 11(1), 39-64.

Clark, A. et al. (1996). Is job satisfaction U - shaped in age? Journal of Occupational and Organizational Psychology, 69(1), 57-81. https://doi.org/10.1111/j.2044-8325.1996.tb00600.x

Cleveland, J. N. et al. (2000). Women and men in organizations: Sex and gender issues at work. Psychology Press.

Dansereau, F. et al. (1975). A vertical dyad linkage approach to leadership within formal organizations: A longitudinal investigation of the role making process. Organizational Behavior and Human Performance, 13(1), 46-78. https://doi.org/10.1016/0030-5073(75)90005-7

Dienesch, R. M., \& Liden, R. C. (1986). Leader-member exchange model of leadership: A critique and further development. Academy of Management Review, 11(3), 618-634. 
Dionne, S. D. et al. (2002). "Neutralizing substitutes for leadership theory: leadership effects and $\begin{array}{llllll}\text { common-source bias. Journal of Applied Pychology, } & 87(3), & 454 .\end{array}$ https://doi.org/10.1037/0021-9010.87.3.454

Dorfman, P. W. et al. (1997). Leadership in Western and Asian countries: Commonalities and differences in effective leadership processes across cultures. The Leadership Quarterly, 8(3), 233-274. https://doi.org/10.1016/S1048-9843(97)90003-5

Durarajend, A. (2004). Leader-member exchange and job satisfaction, Universiti Sains Malaysia. PhD Thesis.

Eagly, A. H. (2003). The Rise of Female Leaders. Zeitschrift FÜR Sozialpsychologie, 34(3), 123-136. https://doi.org/10.1024//0044-3514.34.3.123

Eagly, A. H. (2005). Achieving relational authenticity in leadership: Does gender matter? The Leadership Quarterly,16(3), 459-474. https://doi.org/10.1016/j.leaqua.2005.03.007

Eagly, A. H. et al. (2000). Social role theory of sex differences and similarities: A current appraisal. The Developmental Social Psychology of Gender, 123-174.

Eagly, A. H. et al. (2003). Transformational, transactional, and laissez-faire leadership styles: A meta-analysis comparing women and men. Psychological Bulletin, 129(4), 569. https://doi.org/10.1037/0033-2909.129.4.569

Eagly, A. H., \& Carli, L. L. (2007). Through the labyrinth: The truth about how women become leaders. Harvard Business Press.

Eagly, A. H., \& Karau, S. J. (2002). Role congruity theory of prejudice toward female leaders. Psychological Review, 109(3), 573. https://doi.org/10.1037/0033-295X.109.3.573

Eberl, M. (2010). An application of PLS in multi-group analysis: The need for differentiated corporate-level marketing in the mobile communications industry. Handbook Of Partial Least Squares, Springer: 487-514.

Fletcher, J. K. (2004). The paradox of postheroic leadership: An essay on gender, power, and transformational change. The Leadership Quarterly, 15(5), 647-661. https://doi.org/10.1016/j.leaqua.2004.07.004

Garcia-Retamero, R., \& López-Zafra, E. (2006). Prejudice against women in male-congenial environments: Perceptions of gender role congruity in leadership. Sex Roles, 55(1-2), 51-56. https://doi.org/10.1007/s11199-006-9068-1

Gazioglu, S., \& Tansel, A. (2003). Job satisfaction, work environment and relations with managers in Britain. ERC-Economic Research Center, Middle East Technical University.

Gazioglu, S., \& Tansel, A. (2006). Job satisfaction in Britain: individual and job related factors. Applied Economics, 38(10), 1163-1171. https://doi.org/10.1080/00036840500392987

Gerstner, C. R., \& Day, D. V. (1997). Meta-Analytic review of leader-member exchange theory: Correlates and construct issues. Journal of Applied Psychology, 82(6), 827. https://doi.org/10.1037/0021-9010.82.6.827

Goodhue, D. et al. (2007). Research note-statistical power in analyzing interaction effects: Questioning the advantage of PLS with product indicators. Information Systems Research, 18(2), 211-227. https://doi.org/10.1287/isre.1070.0123

Graen, G. B., \& Uhl-Bien, M. (1995). Relationship-based approach to leadership: Development of leader-member exchange (LMX) theory of leadership over 25 years: Applying a multi-level multi-domain perspective. The Leadership Quarterly, 6(2), 219-247. https://doi.org/10.1016/1048-9843(95)90036-5

Graen, G. et al. (1982). The effects of leader-member exchange and job design on productivity and satisfaction: Testing a dual attachment model. Organizational Behavior and Human Performance, 30(1), 109-131. https://doi.org/10.1016/0030-5073(82)90236-7

Graen, G., \& Cashman, J. F. (1975). A role-making model of leadership in formal organizations: A developmental approach. Leadership Frontiers, 143, 165.

Hackman, J. R., \& Oldham, G. R. (1976). Motivation through the design of work: Test of a theory. Organizational Behavior and Human Performance, 16(2), 250-279. https://doi.org/10.1016/0030-5073(76)90016-7

Hair, J. F. et al. (2006). Multivariate data analysis. Upper Saddle River, NJ: Pearson Prentice Hal

Hair, J. F. et al. (2011). PLS-SEM: Indeed a silver bullet. Journal of Marketing Theory and Practice, 19(2), 


\section{9-152. https://doi.org/10.2753/MTP1069-6679190202}

Hair, J. F. et al. (2012). An assessment of the use of partial least squares structural equation modeling in marketing research. Journal of the Academy of Marketing Science, 40(3): 414-433. https://doi.org/10.1007/s11747-011-0261-6

Hare-Mustin, R. T., \& J. Marecek (1994). Asking the right questions: Feminist psychology and sex differences. Feminism \& Psychology, 4, 531-537. https://doi.org/10.1177/0959353594044007

Henseler, J. et al. (2009). The use of partial least squares path modeling in international marketing. Advances in International Marketing, 20(1), 277-319.

House, R. J. et al. (1997). Cross-cultural research on organizational leadership: A critical analysis and a proposed theory. New Perspectives in International Organizational Psychology. New Lexington, San Francisco.

Johnson, C. et al. (2006). Legitimacy, organizational sex composition, and female leadership. Social Psychology at Workplace, 23, 117-147.

Kark, R. et al. (2012). Does valuing androgyny and femininity lead to a female advantage? The relationship between gender-role, transformational leadership and identification. The Leadership Quarterly, 23(3), 620-640. https://doi.org/10.1016/j.leaqua.2011.12.012

Kim, H., \& Yukl, G. (1998). Relationships of managerial effectiveness and advancement to self-reported and subordinate-reported leadership behaviors from the multiple-linkage model. Monographs in Organizational Behavior and Industrial Relations, 24, 243-260.

Kraimer, M. L. et al. (1999). "Psychological empowerment as a multidimensional construct: A test of construct $\begin{array}{llll}\text { validity. Educational and Psychological Measurement, 59(1), 127-142. } & \text {. }\end{array}$ https://doi.org/10.1177/0013164499591009

Law, K. S. et al. (2010). Currencies of exchange and global LMX: How they affect employee task performance and extra-role performance. Asia Pacific Journal of Management, 27(4), 625-646. https://doi.org/10.1007/s10490-009-9141-8

Leaper, C. (1994). Exploring the consequences of gender segregation on social relationships. New Directions for Child and Adolescent Development, (65), 67-86. https://doi.org/10.1002/cd.23219946507

Lee, J. (2005). Effects of leadership and leader-member exchange on commitment. Leadership \& organization Development Journal, 26(8), 655-672. https://doi.org/10.1108/01437730510633728

Lévy-Garboua, L., \& Montmarquette, C. (2004). Reported job satisfaction: what does it mean? The Journal of Socio-Economics, 33(2), 135-151. https://doi.org/10.1016/j.socec.2003.12.017

Liden, R. C. et al. (1997). Leader-member exchange theory: The past and potential for the future. Research in Personnel and Human Resources Management, 15, 47-120.

Locke, E. A. (1976). The nature and causes of job satisfaction. Handbook of industrial and organizational psychology, 1, 1297-1343.

Mathieu, J. E., \& Zajac, D. M. (1990). A review and meta-analysis of the antecedents, correlates, and consequences of organizational commitment. Psychological Bulletin, 108(2), 171. https://doi.org/10.1037/0033-2909.108.2.171

McDowell, L., \& Bradley, H. (2000). Gender and power in the workplace: Analysing the impact of economic change, JSTOR.

Mehta, C. M., \& Strough, J. (2009). Sex segregation in friendships and normative contexts across the life span. Developmental Review, 29(3), 201-220. https://doi.org/10.1016/j.dr.2009.06.001

Metcalfe, B. D. (2006). Exploring cultural dimensions of gender and management in the Middle East. Thunderbird International Business Review, 48(1), 93-107. https://doi.org/10.1002/tie.20087

Metcalfe, B. D. (2007). Gender and human resource management in the Middle East. The International Journal of Human Resource Management , 18(1), 54-74. https://doi.org/10.1080/09585190601068292

Meyer, J. P., \& Herscovitch, L. (2001). Commitment in the workplace: Toward a general model. Human resource Management Review, 11(3), 299-326. https://doi.org/10.1016/S1053-4822(00)00053-X

Mimouni, F. et al. (2012). 7. Leadership development philosophy and practice in Saudi Arabia. Leadership Development in the Middle East, 169. 
Minkus-McKenna, D. (2009). Women Entrepreneurs in Riyadh, Saudi Arabia. University of Maryland University College (UMUC) Working Paper Series.

Moaddel, M. (2006). The Saudi public speaks: Religion, gender, and politics. International Journal of Middle East Studies, 38(01), 79-108. https://doi.org/10.1017/S0020743806412265

Morgan, R. B. (1989). Reliability and validity of a factor analytically derived measure of leadership behavior and characteristics. Educational and Psychological Measurement, 49(4), 911-919. https://doi.org/10.1177/001316448904900414

Mowday, R. T. et al. (1982). Organizational linkage: the psychology of commitment, absenteeism and turnover. New York, NY.: Academic Press. NHS Information centre .

Nunnally, J. (1978). Psychometric methods. New York: McGraw-Hill.

O'Leary-Kelly, S. W., \& Vokurka, R. J. (1998). The empirical assessment of construct validity. Journal of Operations Management, 16(4), 387-405. https://doi.org/10.1016/S0272-6963(98)00020-5

Omar, A., \& Davidson, M. J. (2001). Women in management: a comparative cross-cultural overview. Cross Cultural Management: An International Journal, 8(3/4), 35-67. https://doi.org/10.1108/13527600110797272

Omer, T. Y. (2005). Leadership style of nurse managers at the Saudi national guard hospitals. Fairfax: George Mason University. PhD Thesis.

O'Reilly, C. A., \& Chatman, J. (1986). Organizational commitment and psychological attachment: The effects of compliance, identification, and internalization on prosocial behavior. Journal Of Applied Psychology, 71(3), 492. https://doi.org/10.1037/0021-9010.71.3.492

Powell, G. N., \& Graves, L. M. (2003). Women and men in management. Los Angeles: Sage.

Ridgeway, C. L., \& Smith-Lovin, L. (1999). The gender system and interaction. Annual Review of Sociology, 191-216. https://doi.org/10.1146/annurev.soc.25.1.191

Runyan, A. S., \& Peterson, V. S. (2013). Global gender issues in the new millennium. Westview Press.

Stringer, L. (2006). The link between the quality of the supervisor-employee relationship and the level of the employee's job satisfaction. Public Organization Review, 6(2), 125-142. https://doi.org/10.1007/s11115-006-0005-0

Takala, T., \& Aaltio, I. (2004). Charismatic leadership and ethics from gender perspective. Verkkojulkaisussa Electronic Journal of Business Ethichs and Organization Studies, 9(2).

Taleb, H. M. (2010). Gender and leadership styles in single-sex academic institutions. International Journal of Educational Management, 24(4), 287-302. https://doi.org/10.1108/09513541011045236

Vidyasagar, G., \& Rea, D. M. (2004). Saudi women doctors: gender and careers within Wahhabic Islam and a 'westernised' work culture. Women's Studies International Forum, Elsevier. https://doi.org/10.1016/j.wsif.2004.06.008

Volmer, J. et al. (2011). Reciprocal relationships between leader-member exchange (LMX) and job satisfaction: A Cross-lagged analysis. Applied Psychology, 60(4), 522-545. https://doi.org/10.1111/j.1464-0597.2011.00446.x

Walker, S. (2004). Women and leadership: A female private institute for higher education, al nour college. Saudi Arabia (Doctoral).

Wikaningrum, T. (2007). Cowrker Exchange, Leader-Member Exchange, and Work Attitudes. Gadjah Mada International Journal of Business, 9(2).

Yaseen, Z. (2010). Leadership styles of men and women in the Arab world. Education, Business and Society: Contemporary Middle Eastern Issues, 3(1), 63-70. https://doi.org/10.1108/17537981011022823

\section{Copyrights}

Copyright for this article is retained by the author(s), with first publication rights granted to the journal.

This is an open-access article distributed under the terms and conditions of the Creative Commons Attribution license (http://creativecommons.org/licenses/by/4.0/). 